\title{
Salvaging a Severely Burned Ankle Using Arthrodesis and Anterolateral Thigh Free Flap
}

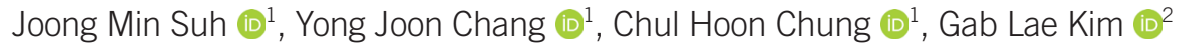 \\ Departments of ${ }^{1}$ Plastic and Reconstructive Surgery and ${ }^{2}$ Orthopaedic Surgery, Hallym University Kangdong Sacred Heart Hospital, Seoul, Korea
}

\begin{abstract}
A 72-year-old male patient without underlying diseases presented with a flame burn injury on the fibula and talus of the ankle joint and soft tissue around the posterior lower leg. Necrotic tissue was removed with surgical debridement. Amputation was considered because loss of the bony structure on the ankle joint, including the fibula, hindered stability of the joint. We covered the soft tissue defect using an anterolateral thigh free flap and salvaged the limb using ankle and subtalar arthrodesis with tibiotalocalcaneal intramedullary nailing. The patient began self-ambulation 1 month after the surgery and did not develop any complications.
\end{abstract}

Keywords: Ankle joint; Salvage therapy; Burns; Arthrodesis; Reconstructive surgical procedures

\section{Introduction}

The human ankle joint maintains stability in a mortise and tenon structure. However, because the soft tissue around the joint is thin, the structures that maintain joint stability, including the ligaments and bone, are more vulnerable to traumatic injury. Here, we present a successful case of covering a severe soft tissue defect and bony structure destruction around the ankle resulting from a flame burn. The procedure enabled ambulation without complications in a patient who had been recommended for amputation at another hospital. The study was approved by the Institutional Review Board of Kangdong Sacred Heart Hospital (IRB No. 2019-11-008) and was conducted in accordance with the principles of the Declaration of Helsinki. Written informed consent was obtained from the patient for publication of his data.

\section{Case}

A 72-year-old man without underlying diseases lost consciousness due to inhalation of charcoal smoke and sustained a deep flame burn injury on his right posterior lower leg. He had been treated for the acute phase in a burn clinic and was referred to our institution for further management. The patient had a severe soft tissue defect from the midpoint of the calf to the posterior side of the ankle joint $(25 \mathrm{~cm}$ in length, $15 \mathrm{~cm}$ in diameter) (Fig. 1). Necrosis occurred in the fibula, talus, and calcaneal bone that comprised the ankle joint, and the surrounding joint capsule and ligaments were also injured. Due to the extensive injury to the bony structures of the ankle joint and osteomyelitis, amputation had been considered. Because early ambulation is important to reduce complications that may occur after lower leg injuries, in severe injuries it is
Case Report

Received: December 18, 2019

Revised: January 28, 2020

Accepted: January 28, 2020

\section{Corresponding author:}

Yong Joon Chang, M.D.

Department of Plastic and Reconstructive Surgery, Hallym University Kangdong Sacred Heart Hospital, 150 Seongan-ro, Gangdong-gu, Seoul 05355, Korea

Tel: +82-2-2224-2246

Fax: +82-2-448-0114

E-mail: drjunys@naver.com

This article was presented at the PRS Korea 2019 on November 9, 2019 in Seoul, Korea.

This is an Open Access article distributed under the terms of the Creative Commons Attribution Non-Commercial License (https://creativecommons.org/licenses/by-nc/4.0/) which permits unrestricted non-commercial use, distribution, and reproduction in any medium, provided the original work is properly cited.

C 2020 Korean Wound Management Society 
Suh JM et al.

Salvage of severely burned ankle joint

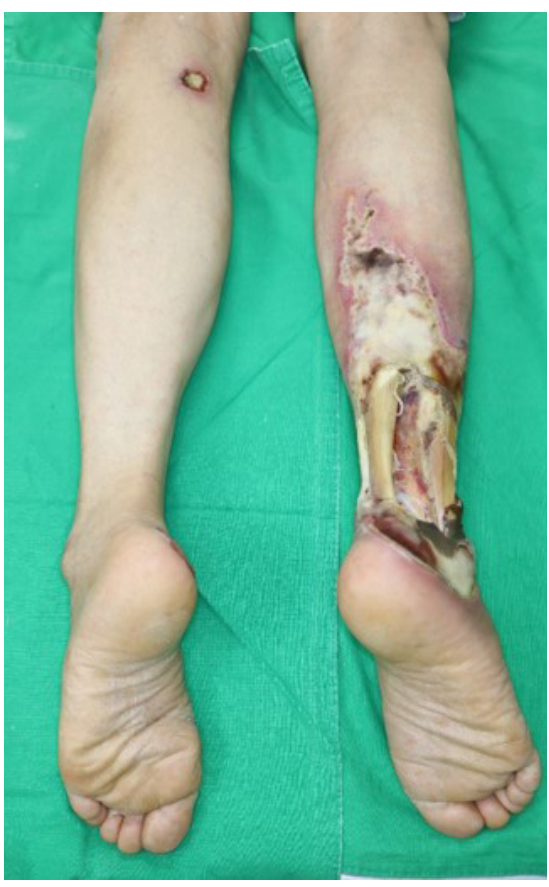

Fig. 1. Preoperative photograph (posterior view). Posterolateral aspect of the right ankle and heel were severely injured.
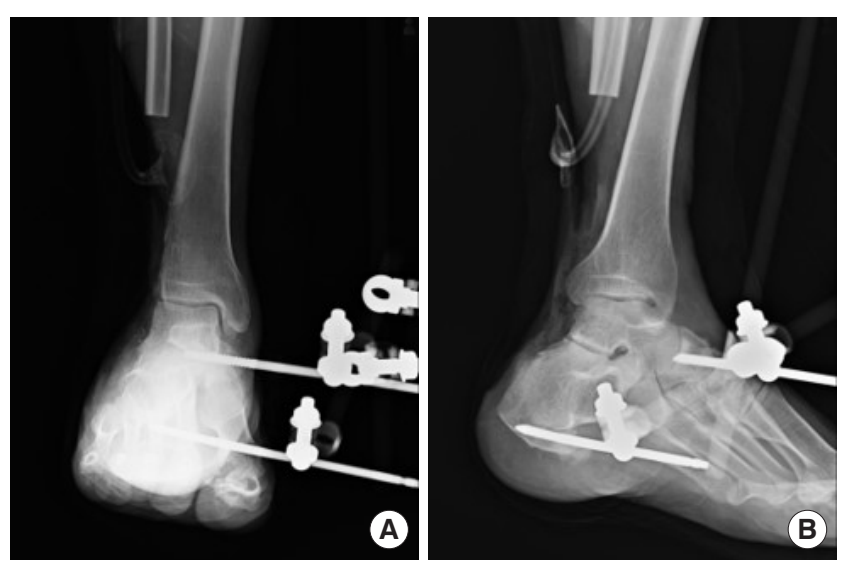

Fig. 2. Postoperative radiographs after serial debridement. The necrotic portions of the fibula and calcaneal bone were debrided and then the external fixator was applied. (A) Anterior-posterior radiograph. (B) Oblique radiograph.

recommended to perform amputation as soon as possible and then to enable early ambulation with a prosthesis. However, patients generally find amputation unacceptable and may suffer psychologically after the operation. Here, the patient also showed a strong fear of amputation and expressed a desire to salvage the limb. Therefore, first we removed the distal half of the fibula, including the lateral malleolus and a part of the ta-

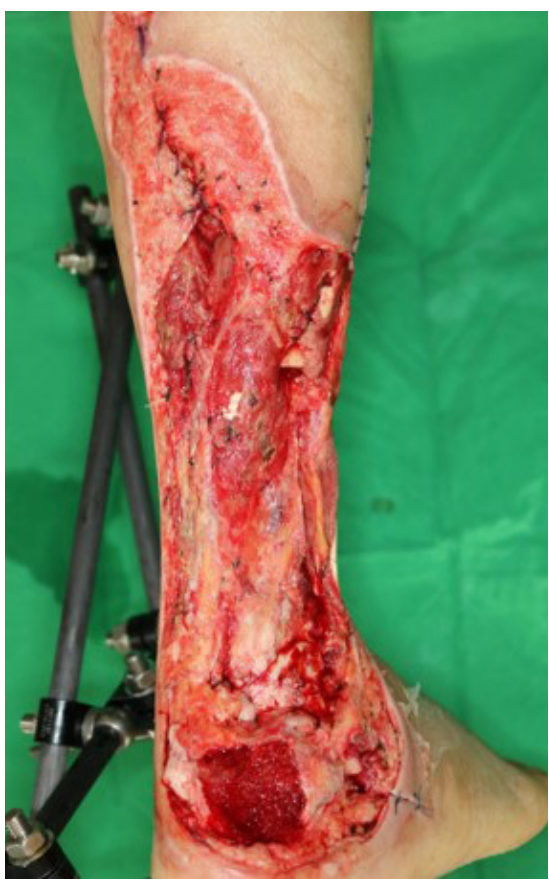

Fig. 3. Photograph taken after serial debridement. Bones were resected from the middle of the fibula to the calcaneal tuberosity, as were all necrotic portions of the Achilles tendon.

lus and calcaneal bone and applied an external fixator (EF) to fix the bony frame (Fig. 2). Then, we performed serial debridement to remove soft tissues showing necrotic change and administered intravenous antibiotics and negative-pressure wound therapy to clean the wound bed (Fig. 3).

Thereafter, we covered the soft tissue defect using an anterolateral thigh free flap and skin graft and temporarily fixed the ankle with an EF. Forty days after surgery, when the flap and skin graft had taken up well, we removed the EF in collaboration with the orthopedic department and fixed the ankle joint using tibiotalocalcaneal (TTC) intramedullary nailing perpendicular to the ground after passing through the calcaneal bone, talus, and tibia in the retrograde direction, along with ankle fusion and Chopart joint fusion to create horizontal stability (Figs. 4, 5). The patient began ambulation rehabilitation from 1 month after surgery and recovered weight-bearing and selfambulation function within 1 month of commencing rehabilitation. One year after surgery, successful union was achieved between the ankle and Chopart joint; however, the subtalar joint showed no union (Fig. 6). Despite the fact that his gait was altered from that before surgery, the patient was adjusting well to daily life. Though he experienced a slight inconvenience in walking, his daily activities did not require too much movement, and the patient was satisfied with the surgery. 

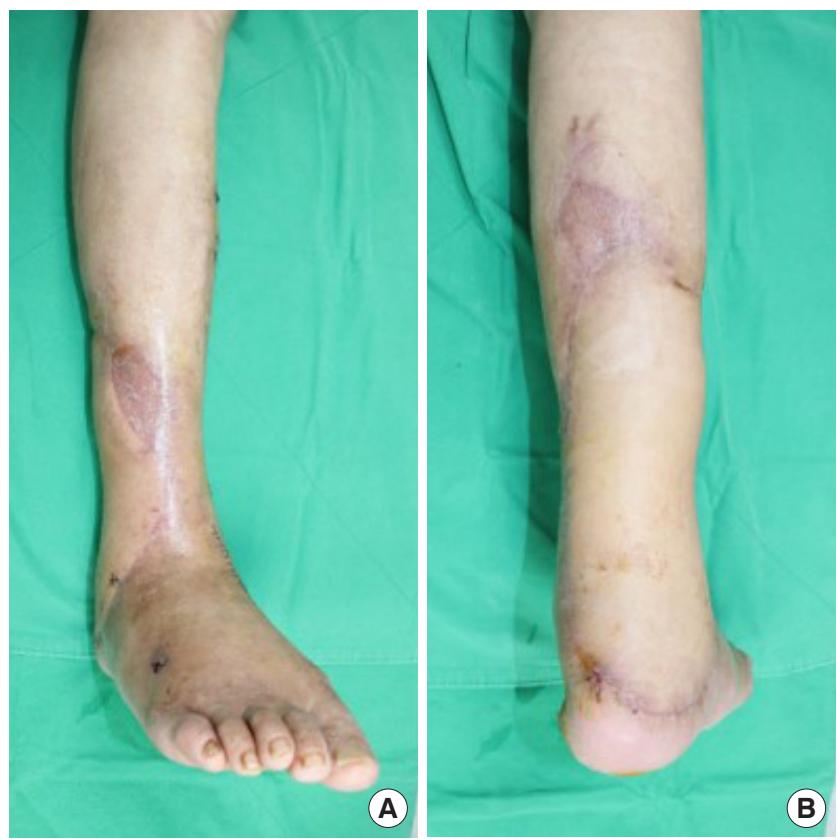

Fig. 4. Photographs obtained 1 week after ankle arthrodesis. (A) Anterior view. (B) Posterior view.
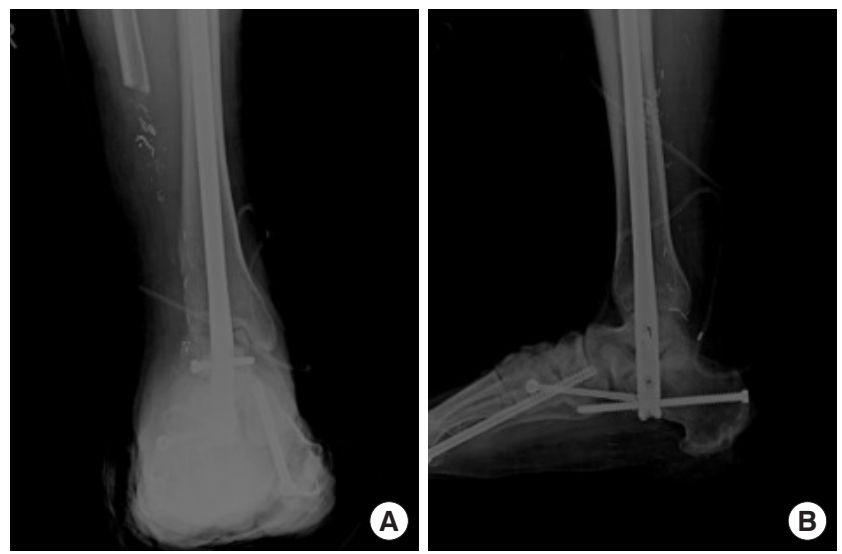

Fig. 5. Radiographs obtained immediately after arthrodesis. (A) Ankle anterior-posterior radiograph. (B) True lateral radiograph.

\section{Discussion}

In this report, we present a case of limb salvage with a relatively intact tibia and calcaneus bone structure in a patient with severe ankle damage. Determining the appropriate reconstruction method is challenging in patients with muscle and bone injuries. Although restoring preoperative function by reconstructing the pre-injury anatomical structures is ideal, devising an appropriate surgical plan in consideration of patient's condition is crucial. In particular, lower limb injuries in older
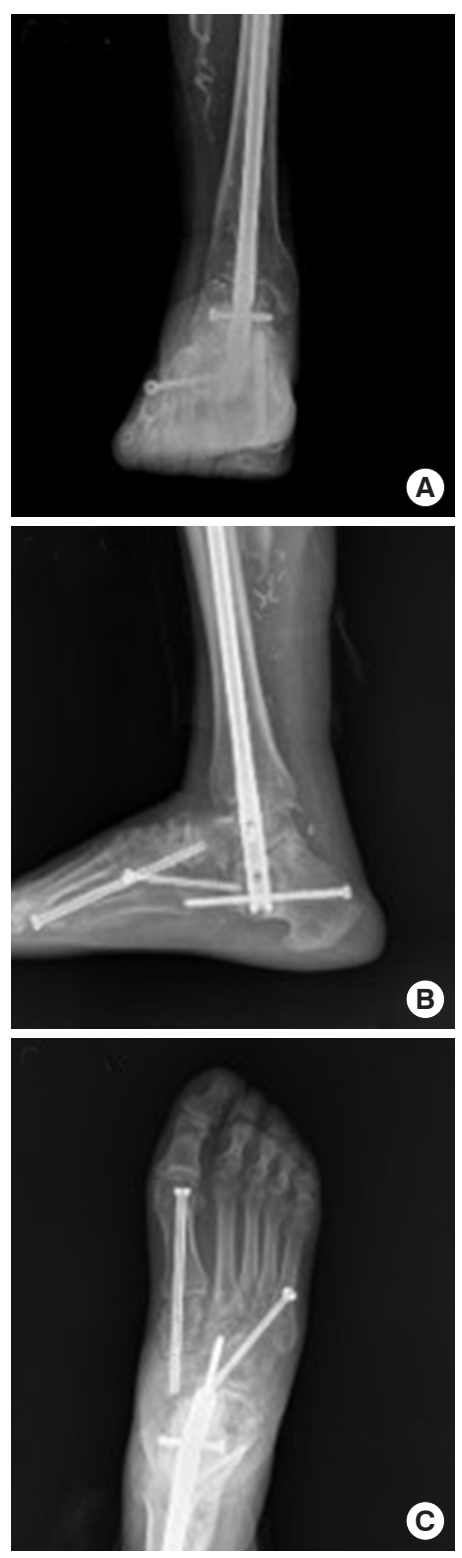

Fig. 6. Radiographs obtained 12 months after arthrodesis. (A) Ankle anterior-posterior radiograph. (B) Lateral radiograph shows successful union of the ankle joint; however, there is no fusion of the subtalar joint. (C) Foot anterior-posterior radiograph shows cannulated screws that were used to stabilize the Chopart joint.

patients may reduce mobility, because a prolonged bed-rest results in reduced muscle tone. In the same way, preexisting morbidities may also be exacerbated, in turn further hindering mobility. Patients who are not independently mobile are at an elevated risk of complications, such as pressure sores, pneumonia, and deep vein thrombosis, and their mortality is increased from these conditions. Treatment that enables weightbearing as rapidly as possible following surgery leads to better 
prognosis in older patients [1,2]. Therefore, if there is severe soft tissue damage, early amputation can be performed in order to shorten the time required until the patient is bearing weight with the prosthesis. However, amputation should be performed with caution, and salvaging the limb should be prioritized in cases where success is likely, particularly considering the postoperative psychological distress an amputation may cause.

The ankle joint maintains stability due to the shape of the talus and its compact placement between the tibia and fibula. The talus is located between the medial and lateral malleoli. The joint capsule, ligaments, muscle, and tendon connect them to maintain ankle joint stability [3]. Although this complex structure gives the ankle joint a wide range of motion, the thin soft tissue surrounding it makes it vulnerable to trauma. The patient in our case had half of the fibula injured, including the lateral malleolus, which damaged the fundamental bony structure of the ankle joint; therefore, amputation had to be considered. However, with amputation, weight bearing is generally started 3 months later; hence, we were concerned that the relatively delayed rehabilitation would decrease mobility and lead to complications. We, therefore, decided first to perform serial debridement and then salvage the limb using ankle fusion, because the tibia, talus, and calcaneal bone were relatively intact.

TTC intramedullary nailing is a fixation technique in which the calcaneus, tibia, and talus are vertically penetrated with a single piece of hardware, and stability of the joint can be attained by fixating the subtalar and tibiotalar joint movement. TTC intramedullary nailing is used as a successful salvage procedure in the presence of a severe injury or deformity of the ankle joint and hindfoot $[4,5]$. According to Al-Nammari et al. [1] and Jonas et al. [2], older patients can reach their preoperative functional level by 6 months after TTC intramedullary nailing, as they have a relatively lower functional demand [6-9]. Our patient started weight-bearing ambulation 1 month following ankle arthrodesis and reached his preoperative functional level without complications by 1 -year follow-up. Although his gait altered from that prior to surgery, he did not have any discomfort in his daily activity.

A number of factors must be considered when planning reconstruction in a patient with severe soft tissue defect from a burn injury. As the field of plastic surgery directs much attention to soft tissue coverage, in most cases, surgeons focus on which flap to use to obtain coverage. However, in patients with severe defects including the joint, surgical planning should take into consideration the patient's ability to resume their normal activity and also the incidence of potential complications.

\section{Conflict of interest}

No potential conflicts of interest relevant to this article are reported.

\section{ORCID iDs}

Joong Min Suh https://orcid.org/0000-0002-3475-0091

Yong Joon Chang https://orcid.org/0000-0003-4966-6543

Chul Hoon Chung https://orcid.org/0000-0003-3722-1838

Gab Lae Kim https://orcid.org/0000-0002-0282-1721

\section{References}

1. Al-Nammari SS, Dawson-Bowling S, Amin A, et al. Fragility fractures of the ankle in the frail elderly patient: treatment with a long calcaneotalotibial nail. Bone Joint J 2014; 96-B:817-22.

2. Jonas SC, Young AF, Curwen $\mathrm{CH}$, et al. Functional outcome following tibio-talar-calcaneal nailing for unstable osteoporotic ankle fractures. Injury 2013;44:994-7.

3. Ray RG. Arthroscopic anatomy of the ankle joint. Clin Podiatr Med Surg 2016;33:467-80.

4. Haaker R, Kohja EY, Wojciechowski M, et al. Tibio-talocalcaneal arthrodesis by a retrograde intramedullary nail. Ortop Traumatol Rehabil 2010;12:245-9.

5. Tarkin IS, Fourman MS. Retrograde hindfoot nailing for acute trauma. Curr Rev Musculoskelet Med 2018;11:43944.

6. Georgiannos D, Lampridis V, Bisbinas I. Fragility fractures of the ankle in the elderly: open reduction and internal fixation versus tibio-talo-calcaneal nailing: short-term results of a prospective randomized-controlled study. Injury 2017; 48:519-24.

7. Nihal A, Gellman RE, Embil JM, et al. Ankle arthrodesis. Foot Ankle Surg 2008;14:1-10.

8. Zak L, Wozasek GE. Tibio-talo-calcaneal fusion after limb salvage procedures: a retrospective study. Injury 2017;48: 1684-8.

9. Chou LB, Mann RA, Yaszay B, et al. Tibiotalocalcaneal arthrodesis. Foot Ankle Int 2000;21:804-8. 